\title{
DEL CENTRO, LA PERIFERIA Y EL CONFLICTO: A PROPOSITO DEL X CONGRESO EUROPEO DE SOCIOLOGIA RURAL
}

Juan Salcedo

Un congreso en España *

No es demasiado frecuente la celebración de congresos científicos de alcance internacional en España, al menos en el área de las ciencias sociales. Las causas pasadas son bien conocidas por todos: excesiva rigidez política hasta fecha bien reciente, limitación de la libertad de expresión, falta de dedi. cación universitaria de muchas de las figuras más destacadas en el terreno académico, penuria económica y un largo etcétera. Por ello, resulta más que llamativa la celebración en Córdoba del X Congreso de la Asociación Europea de Sociología Rural. En efecto, durante los días 5 al 10 del mes de abril nos hemos dado cita en Córdoba más de seiscientas personas, entre sociólogos rurales, sociólogos a secas, periodistas, aficionados, estudiantes y otros profesionales para asistir al primer congreso internacional de Sociología que se celebra en nuestro país.

El mero hecho de su celebración ya merece la atención de todos los interesados en el espinoso terreno de nadie del quehacer sociológico. Cuando ade-

- Agradezco a Jesús de Miguel y a Manuel Pérez-Yruela algunas sugerencias realizadas a la versión original. 
más se conoce un poco a fondo las dificultades de todo tipo (presupuestarias, organizativas y administrativas) que el equipo organizador local tuvo que vencer, no cabe menos que descubrirse y felicitarse porque el congreso se haya realizado. Todo ello disculpa con creces las deficiencias organizativas -que las hubo, como en todo congreso multitudinario- con que algunos congresistas hubieron de enfrentarse.

Pero no voy a hablar de deficiencias, ya que todos los asistentes lo hemos hecho hasta la saciedad, sino de los aspectos científicos que, a mi juicio, son más destacables. Y ello desde mi perspectiva personal de sociólogo no rural, sino de mero asistente curioso a los avatares del Congreso. Como además conozco con cierto detalle algunas de las peripecias que allí tuvieron lugar, me veo en buena situación para dar fe de lo que pasó, y para emitir un juicio (por supuesto parcial) y una evaluación general de los temas que allí se discutieron.

\section{II}

\section{Shils o no Shils}

La idea de que toda sociedad está compuesta de un centro y una periferia pareció ser la tesis científica más importante aceptada en la preparación de este X Congreso Europeo de Sociología Rural. Tanto es así, que se dedicó nada menos que todo un grupo de trabajo a especular sobre el tema de las culturas dominantes y las periféricas. Se asumía quizá que en una sociedad capitalista avanzada, la cultura campesina cumplía el papel de periférica respecto de un sistema de valores dominantes que va por otros derroteros. Y a simple vista parece ser así.

Sin embargo, el tema del centro y la periferia sociales es algo más complejo que no puede darse ni por supuesto, ni como algo establecido sin mayor discusión; por ello parecen necesarias algunas apreciaciones acerca del mismo. Los conceptos de centro y periferia fueron tomados prestados de la geografía y la geopolítica decimonónica por diversos teóricos del imperialismo; como ya se ha puesto de manifiesto en repetidas ocasiones ${ }^{1}$, el imperialismo es concebido por algunos autores marxistas, bien como una forma política de dominación, bien como un conjunto de ideas emergentes de un nivel tecnológico determinado ${ }^{2}$. En cualquier caso, desde principios de siglo a nuestros días, el concepto imperialismo viene siendo usado como una «palabra técnica» que

' Un buen ejemplo del estado actual de la cuestión, en lo que a sus aspectos económicos e ideológicos se refiere, puede verse en el texto de Michael Barrat (1974).

2 Se trata en cierta forma de una extrapolación del modelo tecnológico de cambio social, ya definido por MarX en su conocido capítulo XIV del vol. I de El capital ("Maquinismo y gran industria"). 
designa un estadio superior en el desarrollo capitalista. En nuestros días, el término imperialismo y su homónimo neo-colonialismo son usados para describir el tipo de relaciones desiguales, de dependencia y dominación entre estados, que se dan en esa supuesta fase superior de desarrollo del capitalismo.

Me interesa destacar una vez más que las teorías sobre el imperialismo hacen un uso acrítico de los conceptos centro y periferia bajo los apelativos de metrópoli y colonia. La metrópoli o centro de expansión imperialista dicta normas, valores y órdenes a una burguesía periférica que renuncia a los suyos propios, y que se encuentra ligada a la metrópoli por lazos comerciales, derivados generalmente de la exportación de alguna materia prima. De ahí la denominación de burguesía compradora o exportadora que generalmente se ha dado a esta clase social por parte de algunos teóricos clásicos y modernos ${ }^{3}$. De igual forma lo hacen los teóricos del «colonialismo interno». Lo importante de esta concepción centro-periferia de las relaciones sociales no es, por supuesto, su vertiente espacial, sino su contenido societal, como elemento estructurante de las relaciones sociales y económicas entre clases sociales de dos áreas geográficas bien diferenciadas. En el pensamiento marxista, los conceptos de centro y periferia sociales, aunque centrales para la comprensión de las relaciones de colonización y dominación, aparecen desdibujados, sin un tratamiento específico y definido. Unicamente Gramsci, en su análisis sobre el papel social de los intelectuales ${ }^{4}$ define de forma clara y nítida el concepto de sistema central de creencias y la forma en que los intelectuales desarrollan, modifican o sustituyen ese sistema central.

El análisis sociológico más detallado acerca de los conceptos de centro y periferia y su uso en la teoría sociológica actual es el realizado a lo largo de su obra por Edward Shils, y que ha sido editado recientemente bajo el título de Center and Periphery, Essays in Macrosociology (E. Shils; 1975). A lo largo de las páginas que forman el libro, Shils manifiesta su propósito de profundizar en el estudio de la estructura social que, según su interpretación, es una amalgama de creencias e instituciones estructuradas alrededor de un centro, con la integración como fuerza estructurante. En mi opinión, si bien el análisis estructural de Shils en términos de centro y periferia sociales es lógicamente correcto, no sucede lo mismo con su análisis funcional de la importancia de la integración como elemento estructurador; al destacar la integración como elemento determinante de la estructura social, el autor está cayendo en una falacia, determinada probablemente por la influencia del estructural-funcionalismo en su obra. La obsesión fundamental del quehacer sociológico de Shils es el estudio de la estructura social en términos teóricos. Su vía al conoci-

${ }^{3}$ Entre estos últimos puede citarse, por ejemplo, a Poulantzas (1975).

4 Ver, por ejemplo, Antonio Gramsci 11971, ed.) o el reciente análisis de B. Oltra (1978). De Gramsci son particularmente importantes las ideas contenidas en Gli intellectuali e l'organizzacione della cultura. 
miento de la estructura es original, aunque salpicada de retazos del más puro funcionalismo ideológico, lo cual es natural, dada su colaboración con Talcott Parsons, Janowitz y otros sociólogos funcionalistas de los años cincuenta y sesenta. Esta conexión funcionalista es el elemento disruptor de su bien formulado análisis estructural de la estructura social.

Como es sabido, lo central en la obra de Shils lo constituyen los conceptos de sistema central de valores (central value system) o "conjunto de valores comunes que se encuentran en las decisiones tomadas por las élites dirigentes» ${ }^{5}$, y de sistema institucional central (central institutional system) o "conjunto de instituciones legitimadas por aquél» ${ }^{6}$. Para Shils, la mera existencia de una autoridad cualesquiera se traduce en la imposición de un sistema de valores al conjunto de la sociedad sobre la cual ejerce su influencia. El conjunto formado por la autoridad, con su sistema central de valores y su sistema institucional central construido para defender y propagar aquéllos, es lo que nuestro autor define como centro. Este centro ejercerá una dominación (que en algún caso puede ser carismática) sobre todos aquellos elementos de la sociedad (grupos, clases o individuos) que acepten parcialmente, rechacen o sean indiferentes a esa autoridad valorativa e institucional central; se tratará de la periferia social.

Pero, ¿cómo se ejerce en la realidad la dominación del centro sobre la periferia? Shils cita dos vías: la coerción y el consenso. El autor se decide por el consenso como mecanismo social fundamental de integración social, aunque para ello tenga que soslayar la influencia de dos autores que le son bien conocidos y apreciados ${ }^{7}$ : Aristóteles (La Política) y Hobbes (Leviatán). El consenso es para Shils la única vía hacia la existencia de la sociedad como tal; es también su respuesta a la pregunta clásica de la ciencia social de cómo sea posible el orden social. Así lo manifiesta en repetidas ocasiones, como cuando afirma que «aun en los momentos de crisis revolucionarias existe una gran cantidad de consenso ${ }^{8}$ o cuando - hablando del conflicto de clase-, manifiesta que «está domesticado mediante una fuerte ligazón al sistema central de valores» imperante ${ }^{9}$. Así, desafiando a sus propios genitores intelectuales, Shils se adhiere al principio parsoniano del binomio consensointegración para explicar la dinámica de dominación-sumisión que rigen las relaciones entre el centro y la periferia sociales.

El uso de la integración como elemento estructurador de las relaciones centro-periferia está basado en un razonamiento lógico en el que pueden existir dos falacias. A saber:

- 1. falacia: que la coerción no es válida como mecanismo de dominación durante un periodo largo de tiempo. Esta afirmación, que yo trato

s Edward Shils (1875), pág. 4.

- Ibid., pág. 6.

7 Ibid., págs. XI y XXIX.

- Ibid., pág. 10.

- Ibid., pág. 11. 
como falacia, es citada por Shils en diversas ocasiones. Pero citada como una verdad evidente por sí misma; sin embargo, la historia de la humanidad está llena de pruebas de que esto no es así. Por lo menos existen tantos ejemplos a favor como en contra; no está demostrado que un sistema de dominación de clase no pueda mantenerse en el poder (en el centro) por tiempo indefinido, sobre todo si goza de los adelantos que le proporcionan las nuevas tecnologías al uso.

- 2." falacia: que el binomio coerción-consenso es una dicotomía. También esta afirmación es arbitraria. Cabe más bien suponer que en lugar de una dicotomía se trata de un continuo en el que existen posiciones intermedias, como puede ser la subordinación pasiva, tan características de algunas sociedades campesinas en determinados momentos del tiempo; la subordinación pasiva, a medio camino entre la coerción y el consenso, podría explicar la pervivencia de muchos casos de dominación bastante mejor que el supuesto -e improbable- consenso, que, según Shils, existiría entre los dominados acerca de los dominadores.

La existencia de estas dos falacias en el razonamiento central de Shils es de naturaleza fundamentalmente ideológica. Shils necesita de ambas para montar su complejo entramado acerca de los supuestos integracionistas de la estructura social. Se trata de una concesión a Parsons y a la concepción parsoniana de la cultura como elemento mantenedor del sistema social, como señala Guy Rocher (1972). El problema radica en que la noción de integración no sólo no es necesaria, sino que en más de un sentido es antitética con la realidad social observable, y su uso contribuye a restar capacidad explicativa a algunos de los escritos del autor, como el que se refiere a la «Sociedad de Masas» o el conocido trabajo con Young sobre «El significado de la coronación» ${ }^{10}$, también criticado en este sentido por Norman Birnbaum ${ }^{11}$. Estoy convencida de la validez de la concepción centro-periferia aplicada al análisis de la estructura social. Sin embargo, opino que ese análisis gozaría de mayor capacidad explicativa si se sustituyera el principio de consenso por el de coerción, y se tiende a reconocer (en contra de Parsons) el papel de la subordinación pasiva en el mantenimiento del orden sớcial.

El propio modelo de Shils ganaría en validez si se reconociera que el centro impone su autoridad, sus valores y sus instituciones «ad-hoc» sobre una periferia en un estado de subordinación pasiva no sonsebsual. Así, los estallidos sociales periódicos que sacuden la estructura social de los países en diversos momentos podrían interpretarse como abandonos periódicos de esa sumisión en momentos de rechazo manifiesto de la autoridad impuesta, ya

10 Véase The theory of Mass Society (págs. 91-107) y The meaning of the Coronation (págs. 135-152). (Con M. Young.)

"Monarcas y sociólogos: una respuesta al profesor Shils y al señor Young", en Norman Birmandu (1973). 
sea por una disminución de la coerción, ya por el apoyo (consenso) a un centro alternativo más acorde con los intereses de la periferia que con los del centro tradicional.

\section{III}

\section{Los sociólogos rurales si que son periféricos}

La disgresión anterior está más que justificada si se tiene en cuenta que el tema de la «armonía entre el centro y la periferia sociales» era el leit-motiv oficial del Congreso. Y de hecho, sobre esta dicotomía y sobre los procesos de armonía y desarmonía en el seno de la misma estaban sentadas las bases organizativas de las diferentes sesiones de trabajo. En el fondo de todo parecía detectarse la existencia de un cierto "complejo de inferioridad teórico" que nos presentaba la sociología rural como periférica respecto de la teoría sociológica, y en búsqueda de un mayor status científico y profesional a costa de «armonizarse» con una sociología empírica de orientación funcionalista. Parece como si la pretensión del comité científico organizador hubiera sido la de alcanzar el estadio de «ciencia normal» (en el sentido de Kuhn) a partir de una armonía con la sociología funcionalista de hace veinte años. En este sentido, la denominación de algunos grupos de trabajo era bien reveladora («descentralización política e integración en el sistema»; "cultura dominante y periféricas»; "pobreza rural y marginación social», por citar sólo algunos ejemplos). En realidad, se trataba en convertir la sociología rural en un disciplinado apéndice de la sociología empírica de orientación sistémico-funcionalista.

A lo largo del desarrollo de las sesiones quedó demostrado que si para alguien era periférica la sociología rural, era para el comité científico organizador del Congreso, ya que no para los congresistas. En efecto, el hecho de plantear un Congreso en términos y planteamientos ya superados en otras especializaciones sociológicas, no hacía sino convertir en marginal a la sociología rural respecto del cuerpo general de conocimientos sociológicos. También resultó significativa la exclusión del ala «conflictivista» (Shanin, Galeski) de las actividades organizativas, con lo que el Congreso quedó gravemente escorado hacia la derecha, al menos en su punto de partida.

Sin embargo, el desarrollo del Congreso (el meollo del mismo) pronto demostró lo erróneo de la apreciación de sus organizadores. Dejando aparte algunas ponencias «científicas» (sobre todo en el terreno demográfico) y otras fuertemente funcionalistas, presentadas - curiosamente- por sociólogos de los países socialistas de Europa del Este, el Congreso fue el Congreso de la crítica. Crítica del cuerpo actual de la sociología rural, crítica del estructuralfuncionalismo, crítica de la crítica y crítica del predominio anglosajón en la Asociación Europea de Sociología Rural. 
Antes de seguir adelante he de señalar cómo - a mi juicio- algunos congresistas (españoles periféricos, por más señas) se pasaron, y confundieron un Congreso científico con un foro político. $\mathrm{Y}$ así, los visitantes foráneos pudieron enterarse (éste es el lado positivo) de cómo oprime Madrid a las nacionalidades ( $\mathrm{sic}$ ); de que esas nacionalidades existen desde Indíbil y Mandonio, y de que somos un Estado plurinacional; el problema es que buena parte de estas ponencias encajaban en el nefando "amateurismo sociológico" tan al uso en nuestros lares. Y no hablemos del localismo; algunos hispanos confundieron la sociología rural con hacer un canto a las excelencias de su pueblo y construyeron una sociología amateur de boina y orejeras, que era, en realidad, un compueso de afición, localismo, mala antropología social, peor economía y menos aún de ciencia, con lo que desmerecieron el contexto crítico en que se movían, y nos hicieron en algunas ocasiones añorar el denostado funcionalismo.

Hecha esta salvedad, las perspectivas críticas y conflictivistas fueron las que predominaron en las sesiones, hasta el punto que algún observador cualificado ha señalado cómo la perspectiva oficial fue contestada y cómo se pasó de una perspectiva consensual a otra conflictual en el corto lapso de tres días. A manera de resumen, los logros científicos del Congreso podrían sintetizarse en los puntos siguientes:

\section{Revitalización del concepto de campesinado}

Se trata de la perspectiva patrocinada por Galeski y Shanin, propugnada en nuestro país por E. Sevilla-Guzmán y M. Pérez Yruela, creadores y animadores del Instituto de Estudios Campesinos, dependiente de la Universidad de Córdoba. La revitalización de esta perspectiva se planteó ya desde el comienzo, ya que la conferencia de apertura a cargo del profesor Giner (Brunel University) puso el tema del campesinado sobre el tapete, y ya no se abandonaría hasta la terminación del Congreso.

\section{Relegación de la perspectiva consensual}

También desde el primer momento el estructural funcionalismo es contestado, y las posiciones más radicales, abarcando desde el conflictivismo moderado hasta el maoísmo sociológico más radical, se imponen. Hay que señalar cómo buena parte del radicalismo ha venido de manos de sociólogos o colectivos hispanos, con mejor voluntad que preparación, salvo algunas muy honrosas excepciones. 
3. Predominio del empiricismo y de la especulación metafísica

Como es lógico, la radicalización señalada en el punto anterior, se ha manifestado en una doble dirección: de una parte, hemos asistido a la presentación impávida de una buena serie de trabajos empíricos sin el menor soporte científico ni metodológico; se trataba de una empirie más estrecha que imaginarse pudiera. Algunos datos sobre algún pueblo o comarca, sazonados de buen catecismo y poca imaginación han dado como resultado estudios que ya eran superados por los «estadísticos sociales» del xix. Por otra parte, y en el polo opuesto, también han abundado los socioteólogos del cambio social que nos han bombardeado con sus ideas sobre nacionalismos emergentes y sumentes, sus metafísicas parasociológicas y diversas teorías variopintas, sin mayor apoyo en los datos que alguna vaga referencia al desempleo y la depauperización que sufren los campesinos meridionales (Portugal, España, Italia, Grecia).

$\mathrm{Y}$ no se piense que de las líneas anteriores puede deducirse una visión peyorativa o pesimista del estadio de la sociología rural que ha puesto de manifiesto el Congreso. Al contrario, se trata de las manifestaciones de vitalidad propias de un proceso de redefinición y reorganización, que dará su fruto en un período no demasiado largo.

\section{IV}

\section{Profetas en su tierra}

Ya para terminar, no quiero dejar pasar por alto la oportunidad de comentar un hecho curioso: cómo los escasos sociólogos españoles que ocupan puestos de responsabilidad a escala mundial o europea, están al margen del sistema establecido en nuestro país de cátedras o numerariados. Así, al caso de Juan J. Linz se une ahora el de E. Sevilla, recién elegido vicepresidente de la Asociación Europea de Sociología Rural. Juntos con Pepín Vidal y Manuel Castells (y probablemente alguno más que ahora se me pasa) forman parte de esa minoría con voz y voto en algunos organismos internacionales, pero sin voz, voto ni lugar en los organismos educativos (!) o de investigación (!!!) de nuestro país. 


\section{BIBLIOGRAFIA CITADA}

Barrat, Michael (1974): The Economics of Imperialism, Harmondsworth, Penguin Books.

Birnbaum, N. (1973): Hacia una sociologia critica, Barcelona, Península, 1974.

Gramsci, A. (1971): Selections from the Prison Notebooks, Londres, Lawrence and Wishart.

MANDEL, E. (1964): “After Imperialism?", New Left Review, núm. 25, mayo-junio. MarX, Karl (1867): El capital, México, Ed. del F.C.E. (1966).

Oltra, B. (1978): La imaginación ideológica, Barcelona, Vicens-Vives.

Poulantzas, N. (1974): La crise des dictadures, París, Maspero.

Rocher, G. (1972): Talcott Parsons et la Sociologie americaine, París, P. U.F.

ShIls, E. (1975): Center and Periphery. Chicago, University Press. 